\title{
A Comparative Study of Functional Outcome of Extra Articular Distal Radius Fractures Treated with POP Casing Versus Percutaneous Pinning
}

\author{
Venkateswara Rao Dasari ${ }^{1}$, Shyam Kumar Chinta ${ }^{2}$, Ayyappa Naidu Ch. R.S. ${ }^{3}$, Prudhvi Pinnaka ${ }^{4}$ \\ 1, 2, 3, 4 Department of Orthopaedics, Siddhartha Medical College, Vijayawada, Andhra Pradesh, India.
}

\section{ABSTRACT}

\section{BACKGROUND}

Fractures of the distal radius are common among elderly patients. These injuries result from low energy force. Depending on the functional demand and the nature of the fracture, these fractures may be treated with some form of surgical stabilization. The recovery period of this fracture can be substantial, and the type of treatment for activities of daily living can be significant. The purpose of this study was to assess the functional outcome of extra-articular distal radius fractures treated with casing alone or pinning with casing.

\section{METHODS}

A comparative randomized study comprised of 30 patients with extra-articular distal radius fractures. 15 patients from each group were followed at six weeks and 12 weeks respectively, and the functional outcome was assessed at the end of 3 months after the initiation of treatment.

\section{RESULTS}

Patients who were treated by percutaneous pinning have no better functional outcome than those treated with casing alone, but the complication rate is higher in the casing group than those in the pinning group (P-value: 0.010 ). The radiological and functional outcome has no statistical difference.

\section{CONCLUSIONS}

Both the methods, i.e., casing alone and percutaneous pinning with the casing, have a similar functional outcome, but pinning is superior to casing since there were fewer complications in the pinning group.

\section{KEY WORDS}

Extra-Articular Distal Radius Fractures, Pinning, Casing
Corresponding Author:

Dr. Prudhvi Pinnaka,

Post Graduate, Room No. F1,

Post Graduate Men's Hostel,

Siddhartha Medical College,

Gunadala, Vijayawada-520008,

Andhra Pradesh, India.

E-mail: prudhvi810@gmail.com

DOI: $10.14260 /$ jemds/2022/34

How to Cite This Article:

Dasari VR, Chinta SK, Naidu ACRS. A comparative study of functional outcome of extra articular distal radius fractures treated with pop casing versus percutaneous pinning. J Evolution Med Dent Sci 2022;11(01):179-183, DOI: $10.14260 /$ jemds/2022/34

Submission 26-02-2021,

Peer Review 19-01-2022,

Acceptance 25-01-2022,

Published 29-01-2022.

Copyright (C) 2022 Venkateswara Rao Dasari et al. This is an open access article distributed under Creative Commons Attribution License [Attribution 4.0 International (CC BY 4.0)] 


\section{BACKGROUND}

Distal end radial fractures are the commonest occurring fractures in the upper extremity, and they represent onesixth of all fractures treated in the emergency department. ${ }^{1}$

Fractures of the distal radius are common among elderly patients. ${ }^{2}$ These injuries result from low energy force. Depending on the functional demand and the nature of the fracture, these fractures may be treated with some form of surgical stabilization. Elderly patients often lead a sedentary lifestyle and may have multiple systemic conditions. Patients with distal radius fractures, regardless of the nature of the injury, occasionally may refuse to have surgery or be poor surgical candidates, approximately $10 \%$ of 65 years old will sustain a distal radius fracture during the remainder of their lifetime. ${ }^{3}$ They occur more commonly in women than men with the bimodal occurrence, i.e., young adults and elderly. ${ }^{4}$

Closed reduction and cast immobilization is the mainstay of treatment for minimally displaced, stable fractures ${ }^{1}$. Conservative management is also indicated in unstable fractures in low-demand elderly or those considered too frail to undergo surgery. ${ }^{4}$ For those in advanced age, with low functional demand, injury of the non-dominant hand, extraarticular fracture over the metaphyseal region can be effectively treated by closed reduction and casting. ${ }^{5}$

The method of percutaneous pinning 6 is ideally recommended as a simple way of providing additional stability to immobilization in a cast in extra-articular fractures of the distal radius in which anatomical reduction is obtained by closed reduction. ${ }^{7}$ Determining the best out of the two methods is the purpose of this study.

\section{METHODS}

This prospective study comprised of 30 subjects who attended OPD, they were divided into 2 groups with 15 in each group. One group consisted of patients who were treated by closed reduction and casing and the other by closed reduction and pinning. The functional outcome was assessed at 06 weeks and 12 weeks, respectively.

Following admission, proper history was taken regarding the mode of injury, severity of trauma. All patients were thoroughly examined. Their general condition associated with systemic diseases and associated injuries were noted. All the findings were duly recorded in the proforma.

All patients were carefully inspected for deformity, swelling and ecchymosis. Clinically tenderness, bony irregularity and the relative position of radial and ulnar styloid process were elicited. Movements of the wrist and forearm were checked and found to be painful and limited. Distal vascularity was assessed by radial artery pulsation, capillary filling, pallor and paraesthesia. The involved forearm was immobilized in a below elbow, Plaster of Paris slab and kept elevated. Pain and inflammation were managed using analgesics.

Radiographic views were obtained in anteroposterior view and lateral views. The patients selected randomly for casing alone treatment were treated with conventional reducing manoeuvres, i.e., controlled traction and counter traction followed by below elbow pop casing and asked to actively move fingers, elbow and wrist. Patients selected for pinning were treated with the Kapandji technique. Patients in both groups were followed at four weeks, six weeks and three months, respectively and the final functional outcome on the basis of Gartland and Wereley scoring was done at the end of 3 months.

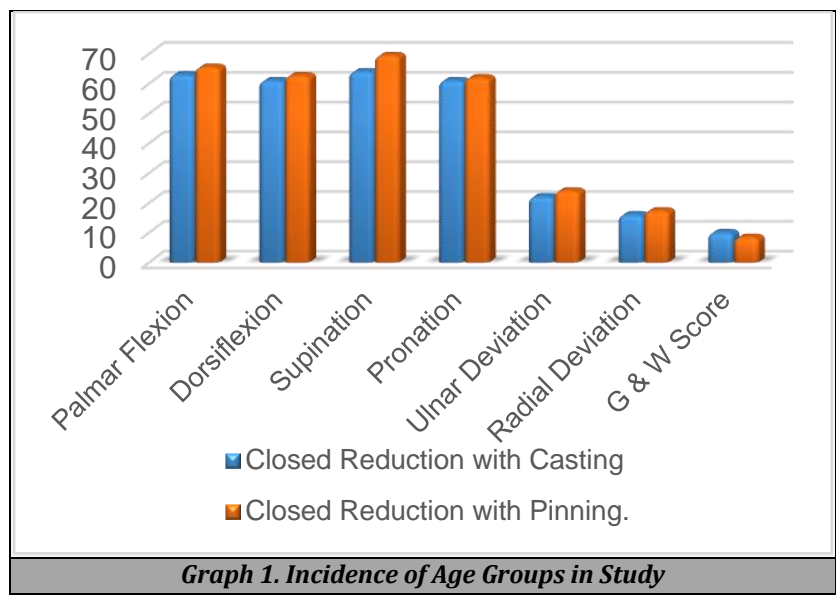

Intermittent follow-ups were done, and necessary dressing at the pinning site and casing status was reviewed. Kirschner wires and casing were removed at 06 weeks follow up.

\section{Study Period}

October 2018- November 2020.

\section{Statistical Analysis}

All the obtained data from selected 30 adult patients of extra articular distal radius fractures were given scoring through Gartland and Wereley scoring system and analysed through SPSS software.

\section{RESULTS}

The mean age of patients in the casing group was 58 , and in the pinning group was 51 . Most of the patients in both groups were between $51-70$ years, i.e., $62 \%$ and all the cases have right-hand incidence, and most of the patients attained injury due to a fall on an outstretched hand (64\%). There was no statistical difference between radiological measurements and the mean range of movements in both groups, but the rate of complications was high in the casing group compared to the pinning group.

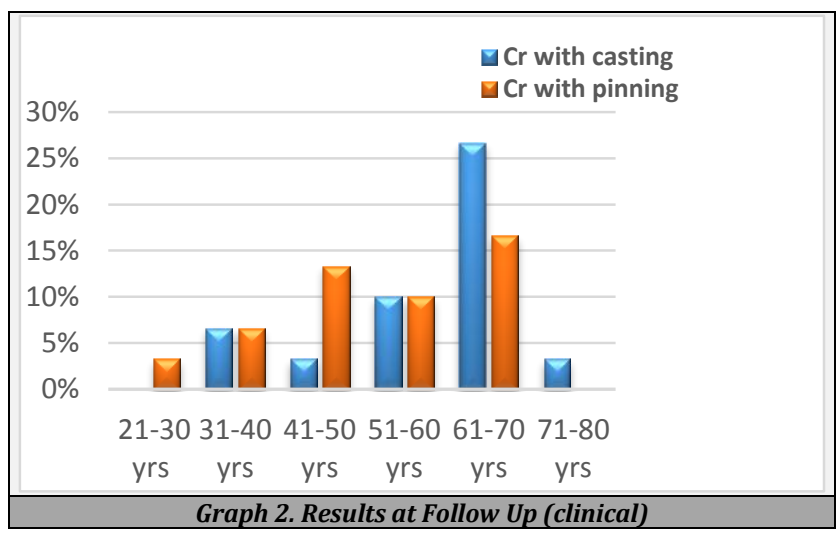


The graph depicting the incidence of age groups involved in the study groups, clearly shows $62 \%$ of the subjects were in the age group of 51-70 years.

There was no statistically significant difference in the range of movements and Gartland and Wereley scoring between both groups.

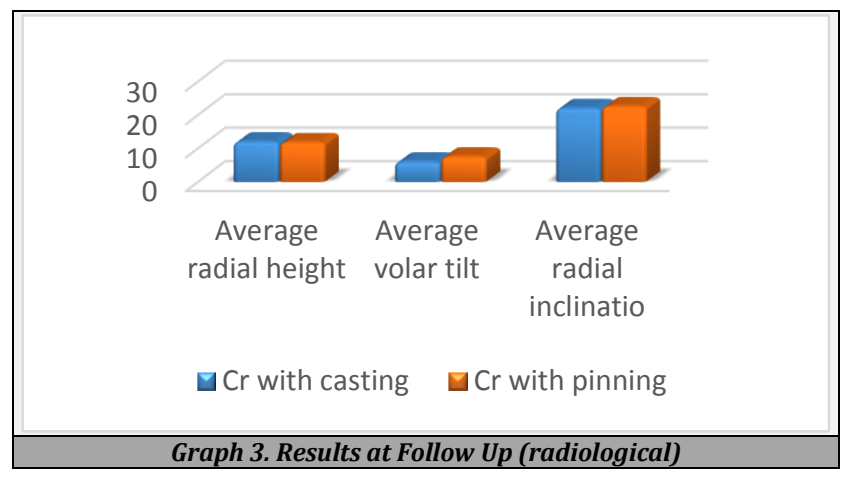

Radiological parameters were assessed for pre-reduction, post-reduction, six weeks and three months. There was no significant difference in all the three parameters, i.e., volar tilt, radial length, radial inclination between both groups at the end of three months.

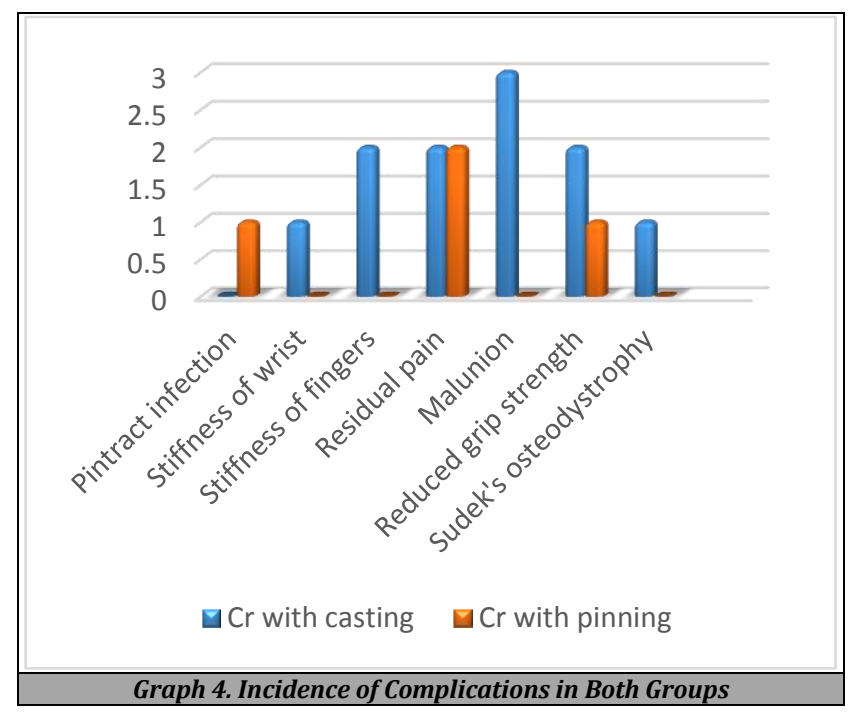

Eleven patients in the casing alone group had complications, and 4 in the pinning group. Based on the presence of complications, there was a significant difference between the two groups (The chi-square statistic is 6.5333 . The $p$-value is.010587. The result is significant at $p<.05$

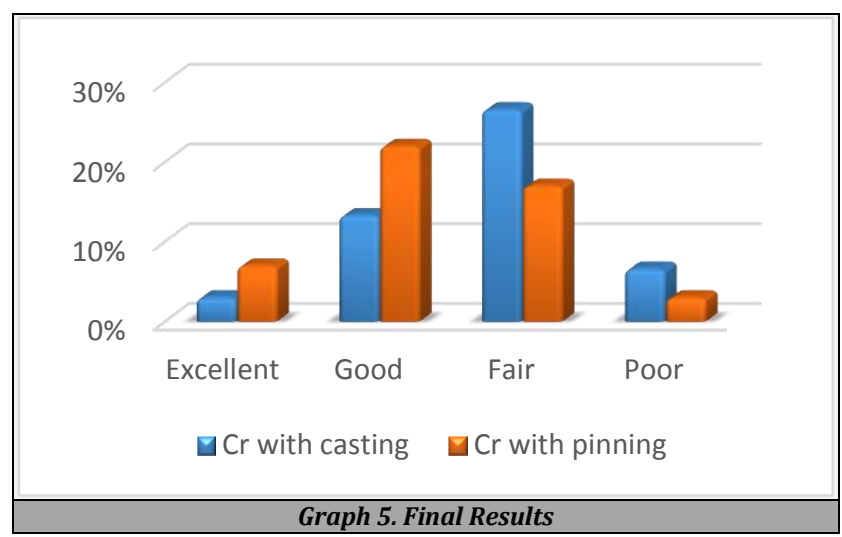

$3 \%$ of cases has shown excellent, $13 \%$ good, $26.6 \%$ fair, $6.6 \%$ poor for casing alone group and $7 \%$ excellent, $22 \%$ good, $17 \%$ fair and $3 \%$ poor in pinning group.

\section{DISCUSSION}

Distal radius fractures are the most common injuries encountered in orthopaedic emergency, especially with an increasing number of low energy fractures in the elderly. History of distal radius dates from 1814, when Abraham Colles $^{1}$ explained this fracture. Management of this fracture and modalities from nonoperative to operative methods has a very long history. Kapandji $5,6,7,8$ in 1976 first described the two-pin technique for distal radius fractures.

Closed reduction and cast immobilization is the most common traditional method but is associated with a high risk of malunion, joint stiffness and painful wrist and often fails to prevent early radial collapse. Hence, this method is for elderly patients. ${ }^{8,9}$ Green $^{10}$ first recommended percutaneous pinning with $\mathrm{K}$-wires as an inexpensive and simple procedure. Most studies attribute poor results of this technique to reflex sympathetic dystrophy, wrist stiffness and radial shortening. ${ }^{11,12}$

Right-sided dominance was seen in all cases in the present study. The mean age of patients in our series was 58 years as compared to 41.4 years in the study conducted by Das et al. ${ }^{11}$

The incidence was high in males than females, $27 \%$ in case of casing alone group, whereas females outnumbered males, i.e., $27 \%$ in the case of pinning and casing group.

All the patients were followed for a duration of 3 months and were reviewed on the second week afterwards on the sixth week and three months. At each visit, the patient was evaluated clinically, and Gartland and Wereley ${ }^{12}$ questionnaire were given to evaluate the functional outcome. P-value at the end of three months was 0.26 , i.e., statistically insignificant and proved no significant difference in functional outcome between two modalities, which is comparable with the results published by Warwick et al. ${ }^{13}$ in 1993, Stoffelen and Broos ${ }^{14}$ in 1998, Simic and Weiland, ${ }^{15}$ Beumer and McQueen, ${ }^{16}$ Handoll and Madhok ${ }^{17}$ in 2003. Similar results were shown by Anzarut et al. ${ }^{18}$ in 2004, Wong et al. $^{3}$ in 2010, Mirhamidi and Bayat ${ }^{19}$ in 2013 \& Kvernmo and Krukhaug20 in 2013. Gartland and Werley ${ }^{12}$ obtained a $68.3 \%$ satisfactory result, and Sarmiento et al. ${ }^{21}$ reported an $82 \%$ satisfactory result treated with the casting technique. In the present study, we found that closed reduction and cast application had good results in three months in which they were evaluated. The pinning group showed a better outcome compared to the casing but statistically insignificant. As for the complications, there were 15 cases in which complication occurred. There were 4 cases in the pinning group that had a complication. In the group of patients who were treated by closed reduction and cast application, there were 11 cases. $\mathrm{P}$ value is 0.010 , which is significant. Both modalities of treating distal radius fractures have shown good result, as concluded by Handoll HH, Vaghela MV, Madhok R.22

For all patients, a thorough clinical examination was carried out; required X-rays were taken, initial treatment was given and admitted as in-patients. After selection of patients 
according to inclusion criteria, careful preoperative planning and evaluation were done, patient was operated for fracture distal end of radius either with closed reduction or closed reduction with percutaneous $\mathrm{K}$-wire and casting.

After meticulous post-operative care, patients were followed up for the clinical and radiological union, complication and functional recovery observation and results were analysed using radiological parameters and functionally by modified Gartland-Werley scoring system. ${ }^{23}$ In closed reduction with casting group, 1 patient had excellent, three patients good, nine patients had fair and remaining two patients had poor results. In closed reduction with percutaneous K-wire and casting group, three patients had excellent, nine patients good, seven patients had fair, and the remaining one patient had poor results.

The volar tilt, radial length, radial inclination at the end of 3 months shows statistically significant improvements in closed reduction with the K-wire group compared to the closed reduction group. Hence, we concluded that closed reduction with percutaneous $\mathrm{K}$-wire fixation under c-arm gives extra stability in the treatment of extra-articular fractures distal end of radius with the good clinical and radiological outcome, due to less complication rate.

The main drawback for this study for statistically insignificant values was less sample size and heterogeneity in selection. For high-quality evidence of good quality results, there should be multicentric studies, controlled good prospective randomized studies. Hence it is concluded from the present study that there is no statistical difference in functional outcome of extra-articular distal radius fractures treated with pop casing versus percutaneous pinning.

\section{CONCLUSIONS}

From the present clinical study, there is no significant difference between functional outcome of fractures treated with either casing or percutaneous pinning. But due to the presence of significant complication rate in casing alone group, it can be concluded that closed reduction with per cutaneous pinning under fluoroscopy guidance is simple, minimally invasive and lesser complications which provides extra stability in the treatment of extra articular fractures of distal end of radius with good clinical and radiological outcome.

Data sharing statement provided by the authors is available with the full text of this article at jemds.com.

Financial or other competing interests: None.

Disclosure forms provided by the authors are available with the full text of this article at jemds.com.

\section{REFERENCES}

[1] Ruch D. Fractures of distal end of Radius and Ulna. In: Bucholz RW, Heckman JD, Court-Brown CM, et al. Rockwood and Green's fractures in adults. $6^{\text {th }}$ edn. Vol. 1. Philadelphia: Lippincot Williams and Wilkins 2006;91062.
[2] Young BT, Rayan M. Outcome following nonoperative treatment of displaced distal radius fractures in lowdemand patients older than 60 years. J Hand Surg Am 2000;25(1):19-28.

[3] Wong TC, Chiu Y, Tsang WL, et al. Casting versus percutaneous pinning for extra-articular fractures of the distal radius in an elderly Chinese population : a prospective randomised controlled trial. J Hand Surg Eur 2010;35(3):202-5.

[4] Naidu SH, Capo JT, Moulton M, et al. Percutaneous pinning of distal radius fractures: a biomechanical study. J Hand Surg Am 1997;22(2):252-7.

[5] Shrestha B, Pandey A, Singh GP, et al. Closed reduction and cast versus percutaneous pinning in distal radius fracture. Journal of University College of Medical Sciences 2017;5(1):1-7.

[6] Jupiter JB, Ring D, Weitzel PP. Surgical treatment of redisplaced fracture of the distal radius in patients older than 60 years. J Hand Surg Am 2002;27(4):714-23.

[7] Ark J, Jupiter JB. The rationale for precise management of distal radius fractures. Orthop Clin North Am 1993;24(2):205-10.

[8] Green DP. Pins and plaster treatment of communited fractures of distal end radius. J Bone Joint Surg Am 1975;57(3):304-10.

[9] Field J, Atkins RM. Algodystrophy is an early feature after Colles' fracture. What are the implications? J Hand Surg Br 1997;22(2):178-82.

[10] Atkins RM, Duckworth T, Kanis JA. Features of algodystrophy after Colles' fracture. J Bone Joint Surg Br 1990;72(1):105-10.

[11] Das AK, Sundaram N, Prasad TG, et al. Percutaneous pinning of non-comminuted extra articular fractures of distal radius. Indian J Orthop 2011;45(5):422-6.

[12] Gartland JJ, Werley CW. Evaluation of healed Colles' fractures. J Bone Joint Surg 1951;33A(4):895-907.

[13] Warwick D, Field J, Prothero D, et al. Function ten years after Colles' fracture. Clin Orthop Relat Res 1993;295:270-4.

[14] Stoffelen DV, Broos PL. Closed reduction versus Kapandji-pinning for extra-articular distal radial fractures. J Hand Surg Br 1999;24(1):89-91.

[15] Simic PM, Weiland AJ. Fractures of the distal aspect of the radius: changes in treatment over the past two decades. Instr Course Lect 2003;52:185-95.

[16] Beumer A, McQueen MM. Fractures of the distal radius in low-demand elderly patients: closed reduction of no value in 53 of 60 wrists. Acta Orthop Scand 2003;74(1):98-100.

[17] Handoll HH, Madhok R. Conservative interventions for treating distal radial fractures in adults. Cochrane Database Syst Rev 2003;2:CD000314.

[18] Anzarut A, Johnson JA, Rowe BH, et al. Radiologic and patientreported functional outcomes in an elderly cohort with conservatively treated distal radius fractures. J Hand Surg Am 2004;29(6):1121-7.

[19] Mirhamidi SM, Bayat FM. A prospective comparison between Kapandji and percutaneous extra-focal fixation in extra articular distal radius fractures. Int J Cli Exp Med 2013;6(2):133-9. 
[20] Kvernmo HD, Krukhaug Y. Treatment of distal radius fractures. Tidsskr Nor Laegeforen 2013;133(4):405-11.

[21] Sarmiento A, Pratt GW, Berry NC, et al. Colles' fractures: functional bracing in supination. J Bone Joint Surg Am 1975;57(3):311-7.
[22] Handoll HHG, Vaghela MV, Madhok R. Percutaneous pinning for treating distal radial fractures in adults. Cochrane Database Syst Rev 2007;(3):CD006080.

[23] Arora R, Gabl M, Erhart S, et al. Aspects of current management of distal radius fractures in the elderly individuals. Geriatr Orthop Surg Rehabil 2011;2(56):187-94 